\section{FRI0312 ARTHRITIS IN PRIMARY SJÖGREN'S SYNDROME: CHARACTERISTICS, OUTCOME AND TREATMENT FROM FRENCH MULTICENTER RETROSPECTIVE STUDY}

A. Mirouse ${ }^{1}$, R. Séror ${ }^{2}$, E. Vicaut ${ }^{3}$, X. Mariette ${ }^{2}$, M. Dougados ${ }^{4}$, A.-L. Fauchais ${ }^{5}$ A. Deroux ${ }^{6}$, N. Costedoat-Chalumeau ${ }^{7}$, J. Sellam ${ }^{8}$, J.-B. Arlet ${ }^{9}$, C. Lavigne $^{10}$, O. Fain ${ }^{1}$, A. Mékinian ${ }^{1}$, on behalf of Club Rhumatismes Inflammation and SNFMI. ${ }^{1}$ Service de médecine interne, Hôpital Saint-Antoine, Paris; ${ }^{2}$ Service de rhumatologie, Hôpital de Bicêtre, Kremlin-Bicêtre; ${ }^{3}$ Service de biostatistiques, Hôpital Lariboisière; ${ }^{4}$ Service de rhumatologie B, Hôpital Cochin, Paris; ${ }^{5}$ Service de rhumatologie, $\mathrm{CHU}$ de Limoges, Limoges; ${ }^{6}$ Service de médecine interne, $\mathrm{CHU}$ de Grenoble, Grenoble; ${ }^{7}$ Service de médecine interne, Hôpital Cochin; ${ }^{8}$ Service de rhumatologie, Hôpital Saint-Antoine; ${ }^{9}$ Service de médecine interne, Hôpital Européen Georges Pompidou, Paris; ${ }^{10}$ Service de médecine interne, CHU Angers, Angers, France

Background: Primary Sjogren's syndrome (pSS) is a chronic inflammatory disorder characterised by diminished lacrimal and salivary gland functions. Joint involvement is reported in $20 \%$ to $60 \%$ of pSS patients, and among them one third of patients present synovitis. There is a lack of data concerning therapeutic management during pSS-associated synovitis.

Objectives: To describe the characteristics and the outcome of pSS associated arthritis and to compare the efficacy of different therapeutic regimen.

Methods: We conducted a retrospective study using Club Rhumatisme and Inflammation (CRI) and French Internal Medicine Society (SNFMI) networks. All patients with a diagnosis of primary Sjögren's Syndrome (pSS) and at least one clinical and/or echographic synovitis were included. Patients with synovitis (cases) were compared to pSS patients without synovitis (controls).

Results: 57 patients (93\% women) were included with a median age of 54 years. ${ }^{45-63}$ Patients with synovitis had more frequently lymph node enlargement $(12.3 \%$ vs. $1.8 \%, p=0.007)$ and a higher ESSDAl score $\left(8^{6-12}\right.$ vs. $\left.2,{ }^{1-4} p<0.0001\right)$. There was no difference concerning CRP levels, rheumatoid factor and CCP-antibodies positivity. Among 57 patients with synovitis, 101 lines of various treatments have been used during the follow-up of 40 [22.5-77] months. First line treatment consisted in steroids alone $(3.5 \%)$, steroids in association $(79 \%)$ with hydroxychloroquine (HCQ) $(49 \%)$, methotrexate (MTX) $(35 \%)$, rituximab (RTX) $(5.3 \%)$ or other immunosuppressive drugs (7\%). The number of complete/partial joint responses significantly increased considering the number of overall lines of treatment for MTX, HCQ and RTX: $52 \%$ for the first line, $76 \%$ for the second line and $83 \%$ for the third line $(p<0.05)$, and data were similar considering each drug separately. There was no difference of efficacy between HCQ, MTX, and RTX concerning tender and swollen joint count, CRP level, ESSDAI score and steroids sparing effect at the end of each drug regimen. We performed a propensity score based analysis to determine whether HCQ, MTX, or RTX treatment was associated with better joint outcome. No difference could be shown for the joint response between three treatment regimen (MTX vs. HCQ, OR 1.55 [0.18-13.55], $p=0.69$; MTX vs. RTX, OR 5.08 [0.49-52.17], $\mathrm{p}=0.17$; HCQ vs. RTX OR 3.28 [0.28-38.02], $\mathrm{p}=0.34)$. All 3 treatments $(\mathrm{HCQ}, \mathrm{MTX}$, and $\mathrm{RTX}$ ) were associated with a significant reduction of ESSDAI score and a significant steroids-sparing effect.

Conclusions: pSS articular manifestations may include synovitis which could mimic rheumatoid arthritis but differ by the absence of structural damage. Even if the use of HCQ, MTX, and RTX seem to be effective for joint involvement, the best regimen remains to be determined.

Disclosure of Interest: None declared

DOI: 10.1136/annrheumdis-2018-eular.4826

\section{$\mathrm{FRI0313}$ \\ A RITUXIMAB AND BELIMUMAB COMBINATION THERAPY IN SLE PATIENTS}

A.A. Mesnyankina, S.K. Soloviev, E.N. Aleksandrova, A.P. Aleksankin, A. A. Novikov, E.A. Aseeva, E.L. Nasonov. V.A. Nasonova Research Institute of Rheumatology, Moscow, Russian Federation

Objectives: To assess the efficacy of a rituximab and belimumab combination therapy in pts with active SLE and dynamics of CD19+ B-lymphocytes count in treated pts.

Methods: The study included 7 SLE pts $(1 \mathrm{M} / 6 \mathrm{~F})$ with high (SLEDAI2K $\geq 10-$ 4pts.) and moderate (SLEDAI2K<10-2pts.) disease activity; out of them 1 patient had lupus nephritis, 1 - vasculitis, and remaining 5 had predominantly mucocutaneous and articular manifestations of SLE. The dose of oral GCs at baseline did not exceed $20 \mathrm{mg} /$ day, two pts were treated with prednisone $5 \mathrm{mg} /$ day. The damage index at baseline was 0 in 3 pts, $\leq 1$ in $3 p t s$, and $\geq 1-$ in 1 patient. Rituximab (RTM) was administered at 500-1000 mg, with subsequent adding of Belimumab (BLM) 3 months later at a standard dosing regimen $10 \mathrm{mg} / \mathrm{kg}$ once a month during 9mo. CD19+ B- lymphocytes counts were obtained before initiation RTM (0), and subsequently after $3,6,9$, and $12 \mathrm{mo}$. Depletion of CD19+ B- lymphocytes after RTM was assessed as the decrease of B-cell counts after $3 \mathrm{mo}<0,0110^{*} 9 / /$, where $010^{*} 9 / /$ was categorised as complete depletion, from 0001 to $0,0110^{*} 9 / /$ - partial depletion, and $>0,01110^{*} 9 / /$ - absence of depletion. The comparison group included 20 pts receiving a single 500-2000 mg dose of RTM.

Results: 6 pts demonstrated the decrease in clinical and laboratory SLE activity, starting from 3mo of follow-up (SLEDAl-2K 0 mo-Me 10, 9;16 3mo-Me 8 , 4;86mo-Me 4, 2;6 9mo-Me 5,4;10 12mo-Me 2 2;6) with RTM+BLM combination therapy. The oral GCs dose was reduced to 7,$55 ; 10 \mathrm{mg} /$ day by $12 \mathrm{mo}$, none of the patient required prednisone dose escalation during follow-up. There were no cases of severe infection. The damage index did not increase by $12 \mathrm{mo}$. The combination therapy reduced the absolute counts of CD19+. B-cells. RTM therapy resulted in complete depletion in 2 pts, in partial depletion - in 3 ; in 1 patient the depletion was not documented. Addition of BLM resulted in slowing down of CD19 + B-cell repopulation (figure 1) among pts with complete and partial depletion (Omo-Me $\left.0,11 \times 10^{9} /[0,1 ; 0,28], 12 \mathrm{mo}-\mathrm{Me} 0,01 \times 10^{9} /[0,0085 ; 0025]\right)$ vs pts receiving RTM monotherapy (0mo-Me 0,1 × 10 $9 /[0,06 ; 0,2], 12 \mathrm{mo}-\mathrm{Me} 0,03 \times 10^{9} /$ I[0,008; 0,08]). The decrease in CD19+ B-cell counts after RTM was also documented in the patient who didn't develop depletion initially (0mo-0,5 10*9/, $12 \mathrm{mo}-$ $\left.0,0410^{*} \mathrm{~g} / \mathrm{I}\right)$. RTM and BLM combination failure, as well as failure of standard GCS and cytostatic based therapy, was documented in one patient with cutaneous, articular and haematological SLE.

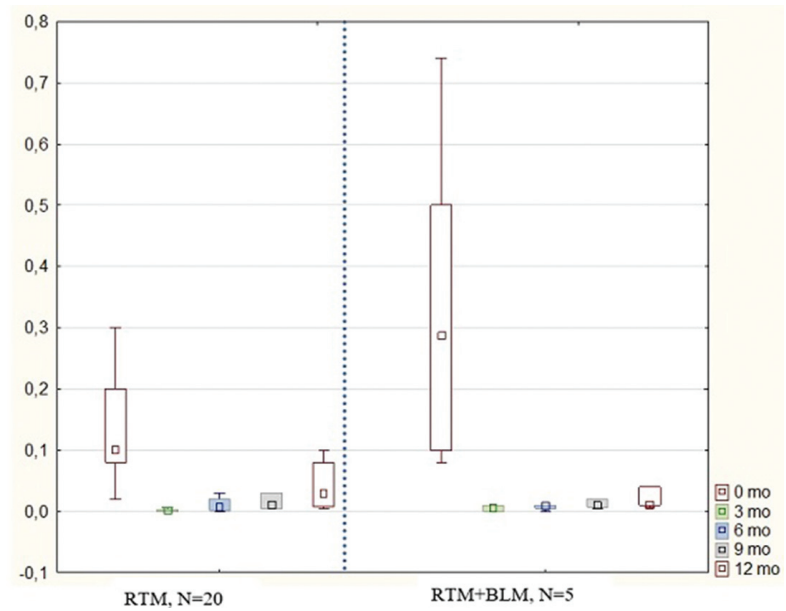

Abstract FRI0313 - Figure 1. Dynamics in CD19+ B-lymphocytes in pts treated RTM and RTM+BLM combination therapy

Conclusions: Combination therapy allows to gain control over disease activity in short time, due to the effect of RTM, while added BLM provides further prolongation of the effect achieved, minimising the risk of exacerbation. This combination may be used as a method of choice in pts with severe SLE involving vital organs, and in persistent cutaneous-articular disease and high immunological activity. Of notice is the fact, that use of RTM and BLM combination allowed to manage all pts on low and medium doses of GCs starting from RTM and BLM initiation and during the entire follow-up, thereby reducing the risk of irreversible organ damage. In these patients there were no signs of infection.

Disclosure of Interest: None declared

DOI: 10.1136/annrheumdis-2018-eular.2475

\section{FRI0314 RISK OF OPHTHALMOLOGIC COMPLICATIONS AS A RESULT OF HYDROXYCHLOROQUINE THERAPY}

\section{A. Khaleel. Rhuematology, Nottingham University NHS Trust, Nottingham, UK}

Background: Hydroxychloroquine is a drug therapy licensed for patients with cutaneous and systemic lupus. A major side effect is maculopathy that can result in permanent visual loss. Often, symptoms are preceded by signs, and screening for preclinical retinopathy can decrease incidence and development of 'bullseye retinopathy ${ }^{1,2}$. More recent high quality studies suggest cases of confirmed toxicity in $1 \%$ of patients at $5-7$ years and therefore documentation of monitoring is imperative ${ }^{3,4}$

Objectives: In accordance with the, British Rheumatology Society guidelines 2008 an audit was carried out in March 2017 to assess whether patients on hydroxychloroquine were being monitored for maculopathy while on therapy.

Methods: The sample group comprised of 76 patients who were on active hydroxychloroquine treatment for SLE, chosen through randomised compute generated numbers. Electronic notes for individual patients over the last 12 months was reviewed for mention of ophthalmologic monitoring, indicating the clinician is aware and surveilling possible signs of toxicity. 
Results: Of all patients on hydroxychloroquine (regardless of dose), 64\% of patients had no mention of ophthalmologic monitoring on their documented clinic letter. Documentation of monitoring did not vary by dose, despite the increased risk of toxicity for those on $400 \mathrm{mg}$ daily.

\begin{tabular}{lcc}
\hline \multicolumn{3}{l}{ Table to show percentage of electronic documentation of patients screened on } \\
hydroxychloroquine & documented(\%) & undocumented(\%) \\
\hline Hydroxychloroquine & 35 & 65 \\
$\mathbf{2 0 0} \mathbf{~ m g}$ daily & 44 & 54 \\
$\mathbf{4 0 0} \mathbf{~ m g}$ daily & 0 & 100 \\
$\mathbf{2 0 0} \mathbf{~ m g} / \mathbf{4 0 0} \mathbf{~ m g}$ alternate days &
\end{tabular}

This audit suggests that Queens Medical Centre patients are not meeting the set standard of ophthalmological review.

Column chart comparing the number of patients with documented evidence of ophthalmologic mention

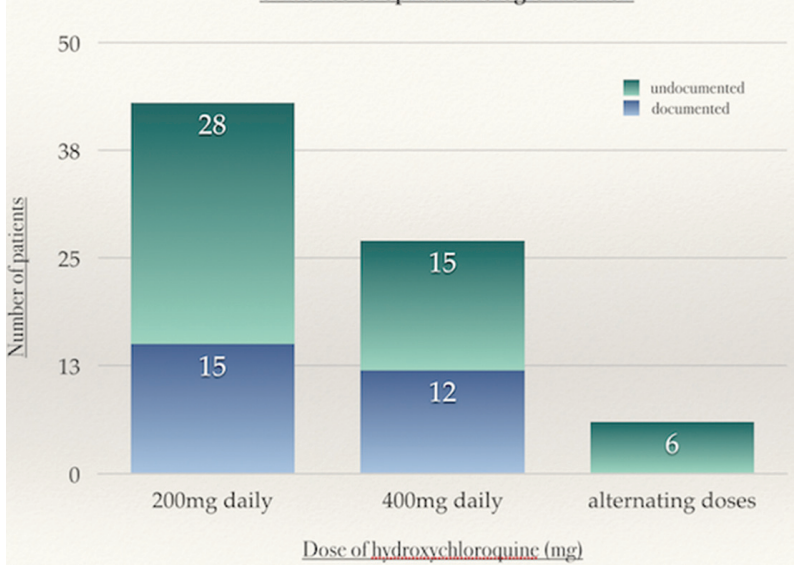

Conclusions: The BSR guidelines have highlighted that there are organisational barriers to monitoring, but acknowledges that ophthalmological risks are present with the use of continued hydroxychloroquine therapy. High risk patients with existing or early signs of visual involvement, should be selected for early assessment and more vigilant follow up. SD-OCT was found to be significantly more cost effective than standard ophthalmological examination ${ }^{5}$. It should be acknowledged that the results of the audit reflect documentation as opposed to practice. Mention of ophthalmological monitoring does not ensure that doctors are actually asking about visual problems. Guidelines have since been updated in April 2017 that recommend annual screening only after 5 years of therapy is sufficient but with a full ophthalmological screening by an ophthalmologist.

\section{REFERENCES:}

[1] Melles R, Marmor M. The Risk of Toxic Retinopathy in Patients on Longterm Hy-droxychloroquine Therapy. JAMA Ophthalmology 2014;132 (12):1453.

[2] Iselin K, Marti P, Pless M. Hydroxychloroquine-Induced Retinal Toxicity. Klinische Monatsblätter für Augenheilkunde. 2016;233(04):514-516.

[3] Wolfe F, Marmor M. Rates and predictors of hydroxychloroquine retinal toxicity in patients with rheumatoid arthritis and systemic lupus erythematosus. Arthritis Care \& Research 2010;62(6):775-784.

[4] Silman A, Shipley M. Ophthalmological monitoring for hydroxychloroquine toxicity: a scientific review of available data. Rheumatology 1997;36 (5):599-601.

[5.] Olson J, Sharp P, Goatman K, Prescott G, Scotland G, Fleming A, et al. Improving the economic value of photographic screening for optical coherence tomography-detectable macular oedema: a prospective, multicentre, UK study. Health Technology Assessment 2013;17(51).

Acknowledgements: I would like to thank Dr Anindya Gupta for his support and helpful mentoring

Disclosure of Interest: None declared

DOI: 10.1136/annrheumdis-2018-eular.1729

\section{FRI0315}

SAFETY, TOLERABILITY, PHARMACOKINETIC AND PHARMACODYNAMIC EFFECTS OF BIIB059, A MONOCLONAL ANTIBODY TARGETING BDCA2 FOLLOWING INTRAVENOUS (IV) AND SUBCUTANEOUS (SC) SINGLE OR MULTIPLE DOSES ADMINISTRATION IN HEALTHY VOLOUNTEERS (HV) AND SUBJECTS WITH ACTIVE SYSTEMIC LUPUS ERYTHEMATOSUS (SLE)

C. Barbey ${ }^{1}$, H. Naik ${ }^{2}$, C. Musselli ${ }^{2}$, R. Christmann ${ }^{2}$, L. Stevenson ${ }^{2}$, D. Rabah², P. Gulati ${ }^{2}$, N. Franchimont ${ }^{2} .{ }^{1}$ Ophtalmology, Pain, New Indication Unit, Biogen, Zug, Switzerland; ${ }^{2}$ Ophtalmology, Pain, New Indication Unit, Biogen, Cambridge, MA, USA

Background: BDCA2 is a plasmacytoid dendritic cell (pDC)-specific receptor that, upon activation, inhibits the inflammatory factors production by human pDCs, including IFN- $\alpha$ a major player in the pathogenesis of SLE. This 3-Part Phase 1 study evaluated the safety, tolerability, pharmacokinetics (PK), pharmacodynamics (PD) and clinical efficacy of single and multiple ascending doses (SAD-MAD) of BIIB059 in HV and SLE subjects (NCT02106897).

Objectives: To compare PK and PD parameters between HV and SLE following single and multiple dose administration of BlIB059

Methods: In the SAD Part 2, 12 subjects with active SLE were randomised 2:1 to receive a single $20 \mathrm{mg} / \mathrm{kg}$ IV dose of BIIB059 or placebo. In the MAD Part $3, \mathrm{HV}$ received either 2 or $3 \mathrm{SC}$ administrations of Placebo or BIIB059 20,50 or $150 \mathrm{mg}$ ) Q4W or 3 SC $300 \mathrm{mg}$ Q2W. Subjects with active SLE, received either 2 or 3 SC placebo or BIIB059 $50 \mathrm{mg}$ or $300 \mathrm{mg}$. The dose levels were selected based on emerging data from the Part 1 in $\mathrm{HV}$ and was not to exceed the maximum tolerated dose. Blood samples were obtained before and after each dose administration to characterise PK and PD (BDCA2 on pDC) relationship for BIIB059.

Results: Part 1 PK and PD results (SAD) in HV and Part 2 PD results have been previously presented ${ }^{1-2}$. In Part 2 of the study, following IV administration, mean $\mathrm{t}_{1 / 2}$ in SLE subjects was 18.1 days, with a mean $\mathrm{CL}$ of $0.251 \mathrm{~L} /$ day and a mean volume of distribution $\mathrm{V}_{\mathrm{ss}}$ of $5.41 \mathrm{~L}$. Following $\mathrm{SC}$ administration, in Part $3 \mathrm{a}$, mean $\mathrm{t}_{1 / 2}$ in $\mathrm{HV}$ subjects ranged from 13.3 to 19.5 days, mean $\mathrm{CL}_{\mathrm{ss}} / \mathrm{F}$ ranged from 0 . 267 to to $0.367 \mathrm{~L} /$ day and $\mathrm{V}_{\mathrm{z}} / \mathrm{F}$ ranged from 7.23 to $9.36 \mathrm{~L}$. In Part $3 \mathrm{~b}$, mean $\mathrm{t}_{1 / 2}$ in SLE subjects ranged from 12.6 to 20.5 days with a mean $\mathrm{CL}_{\text {ss }} / \mathrm{F}$ of 0.455 to $0.485 \mathrm{~L} /$ day and a mean $\mathrm{V}_{\mathrm{z}} / \mathrm{F}$ of 5.93 and $12.8 \mathrm{~L}$. Exposure (AUC and $\mathrm{Cmax}$ ) for BIIB059 increased with dose in both HV and SLE subjects. However exposure in SLE subjects was approximately $40 \%$ lower compared to HV which could not be attributed to body weight differences. The observed mean accumulation ratio for AUC was slightly lower in SLE subjects (2.58) compared to HV (2.66) after BIIB059 SC administration. Complete BDCA2 internalisation was achieved at all dose levels, the duration of which was dose dependent, and similar for $\mathrm{HV}$ and SLE subjects. Reappearance of BDCA2 on circulating pDCs occurred when serum concentrations of BIIB059 dropped to $\sim 1 \mu \mathrm{g} / \mathrm{mL}$. Single and multiple IV and SC doses of BIIB059 appeared to be well-tolerated in HV and SLE subjects. Conclusions: BIIB059 was generally well tolerated. Exposure in SLE subjects was lower compared to $\mathrm{HV}$ while BDCA2 internalisation was similar. Based on the Phase 1 data, BIIB059 is currently evaluated in a Phase 2 trial (NCT02847598).

\section{REFERENCES:}

[1] Martin D, et al. Poster 774. Arthritis Rheumatol. 2016;68(suppl10).

[2] Furie R, et al. Abstract 2013. Arthritis Rheumatol. 2016;68(suppl10).

Disclosure of Interest: C. Barbey Shareholder of: Biogen, Employee of: Biogen, H. Naik Shareholder of: Biogen, Employee of: Biogen, C. Musselli Shareholder of: Biogen, Employee of: Biogen, R. Christmann Shareholder of: Biogen, Employee of: Biogen, L. Stevenson Shareholder of: Biogen, Employee of: Biogen, D. Rabah Shareholder of: Biogen, Employee of: Biogen, P. Gulati Shareholder of: Biogen, Employee of: Biogen, N. Franchimont Shareholder of: Biogen, Employee of Biogen

DOI: 10.1136/annrheumdis-2018-eular.2619 